University of Nebraska - Lincoln

DigitalCommons@University of Nebraska - Lincoln

1982

\title{
A Digital Archive of Northern Hemisphere Snow Cover, November 1966 through December 1980
}

Kenneth F. Dewey

Richard Heim Jr.

Follow this and additional works at: https://digitalcommons.unl.edu/natrespapers

Part of the Natural Resources and Conservation Commons, Natural Resources Management and Policy Commons, and the Other Environmental Sciences Commons

This Article is brought to you for free and open access by the Natural Resources, School of at DigitalCommons@University of Nebraska - Lincoln. It has been accepted for inclusion in Papers in Natural Resources by an authorized administrator of DigitalCommons@University of Nebraska - Lincoln. 


\begin{abstract}
The purpose of this article is to acquaint the research community with a new data base-a digitized archive of Northern Hemisphere snow cover. Historically, those researchers who needed snow cover data for climatic and atmospheric boundary layer studies have had to rely on the irregularly spaced (and in some regions, sparse) grid of point observations. Northern Hemisphere Weekly Snow and Ice Cover Charts, which are created from analyzed satellite imagery at the National Earth Satellite Service (NESS), have been available on an operational basis since late 1966. Each of these weekly charts for the period November 1966 through December 1980 was digitized and stored in a new data archive. Snow cover area and snow cover frequency climatologies were created and examples are presented. The significance of this unique data archive is examined by comparing the 14-year mean annual snow cover frequency climatology with several published snow cover climatologies. The potential uses for this data archive in meteorological and climatological studies also are reviewed.
\end{abstract}

\section{Introduction}

Numerous researchers (Namias 1960, 1962; Kukla and Kukla 1974; Lamb 1955, 1972; Dickson and Namias, 1976) have argued that there is a significant interaction between the extent of snow cover and synoptic-scale atmospheric conditions. The World Meteorological Organization (WMO) also has recommended that "Sensitivity studies should be conducted using general circulation models, with special attention being paid to possible feedbacks-for example, between snow cover and temperature. Global monitoring of the extent and albedo of snow cover by satellite should be included in both short-term and long-term observational programs" (WMO, 1975, p. 62). One of the limiting factors in the study of this interaction has been the lack of digitized snow cover data. However, a continuous archive of snow cover data has existed in map form since 1966 in the form of the Northern Hemisphere Weekly Snow and Ice Cover Charts. These snow and ice boundary maps (drawn on a 1:50,000,000 polar stereographic projection of the Northern Hemisphere) are prepared by the Synoptic Analysis Branch of the National Earth Satellite Service (NESS). As outlined by Matson and Wiesnet (1981), "early in each week the analyst, a satellite meteorologist, makes a pencil trace of the previous week's chart. Daily he collects all of the visual band data received during the previous day, compares snow and ice cover inter- preted from the imagery with snow cover on the previous week's chart, and makes changes." The analyst also examines the surface synoptic data in order to confirm any drastic changes in snow cover due to new snowfall or rapid snow melt. Consequently, each weekly chart incorporates the snow boundary changes observed during the week.

Several researchers have utilized these maps to create a subjectively derived climatology of monthly snow cover areas. Matson (1977), for example, created 10-year mean monthly snow cover boundary maps for the months December through March. The boundary on each weekly map was transferred onto sheets of tracing paper, the weekly overlay sheets were superimposed and registered, and a subjective monthly mean snow cover boundary was drawn by visual integration. All of the monthly maps for each winter month were registered and a subjective 10-year snow cover boundary was drawn by visual integration. Robock (1980) constructed monthly maps for the eight remaining months using the same procedure. As noted by Robock (1980), one of the significant sources of error involved in this technique is "the subjectiveness of the analog averaging of weekly maps to monthly maps to ten-year average monthly maps." The detail and accuracy involved in the preparation of these weekly charts probably have improved through time (Matson and Wiesnet, 1981). Summer snow cover in the Himalayas, for example, was not mapped consistently during the early part of the data period. However, since it is recognized that the NESS charts are the only complete record of Northern Hemisphere snow cover dating back to the mid-1960s, the decision was made to convert all of the weekly charts to a digitized format and then subject them to objective analysis. It should be noted that there are several advantages inherent in the use of satellite-derived snow cover data when compared to other forms or types of data. Satellite observations provide instantaneous collection of data over extensive areas, allowing comparison of data from different regions while utilizing a common data base and uniform collection or observation procedures. Historically, the only source of snow cover data was once-a-day point observations at locations clustered primarily in midlatitude populated areas. However, the satellite imagery utilized to produce the weekly charts provides us with the first spatially-continuous data archive for snow cover.

The Northern Hemisphere Weekly Snow and Ice Cover Charts were digitized using an $89 \times 89$ grid matrix (Fig. 1) covering the entire Northern Hemisphere (except for portions of the tropics). The latitude and longitude of the lower left corner of each grid box and the true surface area of each of the 7921 grid boxes were stored in the data archive. This 


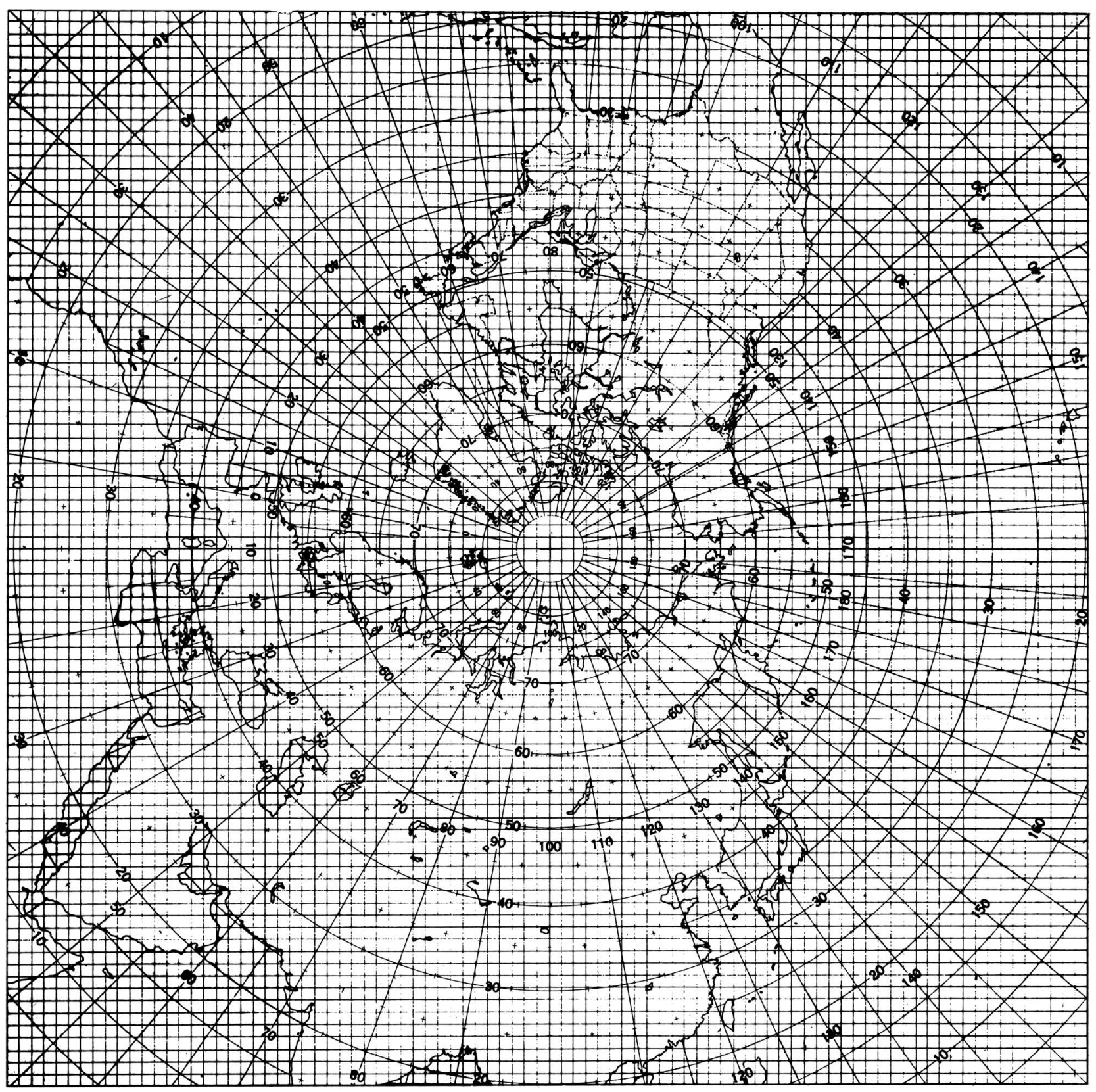

FIG. 1. The $89 \times 89$ grid matrix that was utilized to digitize the NESS weekly snow cover charts.

grid is the same as that used for the satellite-based earth radiation budget atlas of Winston et al. (1979).

An example of a Northern Hemisphere Weekly Snow and Ice Cover Chart is illustrated in Fig. 2. During the digitization process, a grid box that was at least half covered by snow was considered to be completely covered, and any grid box less than half covered was considered to be "open." The land grid boxes north of the circle of nonillumination, which is delineated by a solid line and labeled "DARK" on the weekly charts (see Fig. 2), were considered to be snow-covered during the low-sun season. The weekly charts prepared by NESS also included three categories of reflectivity. It should be noted that the procedure to determine reflectivity is highly subjective and varies considerably from analyst to analyst (Matson and Wiesnet, 1981). The more recent charts have much more reflectivity detail on them compared to the earlier charts in which, for example, North America would be divided into only three or four areas of differing reflectivity. Because of these difficulties, the charts were digitized without considering reflectivity.

The purpose of this paper is to illustrate several examples of the snow cover area and snow cover frequency climatologies that can be created utilizing this unique digitized data base. The significance of these snow cover climatologies will 


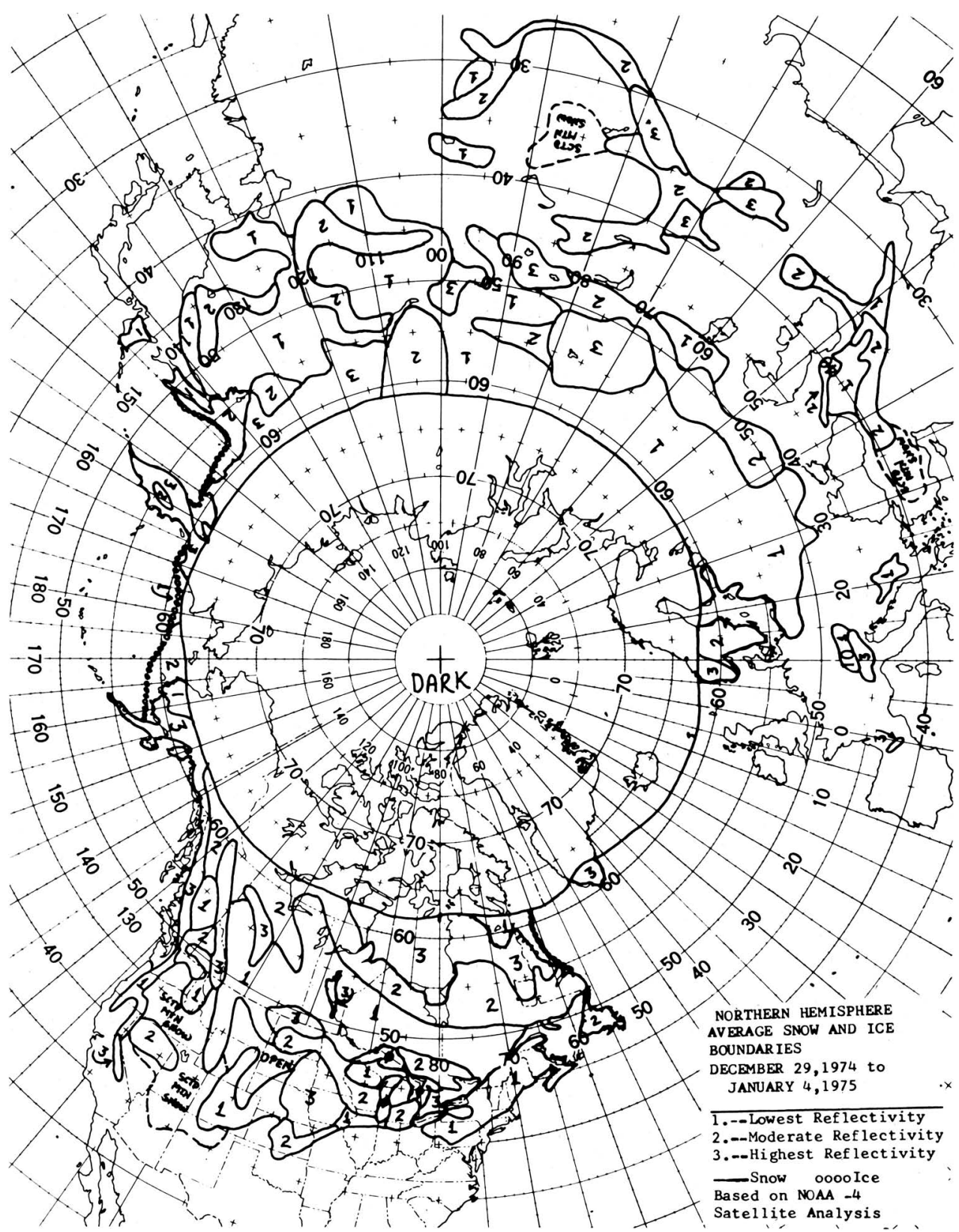

FIG. 2. An example of a Northern Hemisphere Weekly Snow and Ice Cover Chart for the period 29 December 1974-4 January 1975.

be evaluated by comparing the 14 -year mean annual snow cover frequency climatology with several other established snow cover climatologies.

\section{Digitized snow cover products}

Once the weekly charts were converted into a digitized format, several snow cover climatologies were created. The two general types of digitized snow cover products that were created from this data archive are: 1) computed snow cover areas (geographic areal extent in square kilometers), including snow cover area averages and time series of snow cover area variations, and 2) snow cover frequency maps illustrating weekly and seasonal frequencies as well as seasonal anomalies in snow cover frequency.

\section{a. Northern Hemisphere snow cover areas}

The snow cover area could not be measured directly from the number of grid boxes that were indicated as snow covered, due to the polar stereographic projection of the snow cover maps (the area of each grid box varies with latitude). There- 


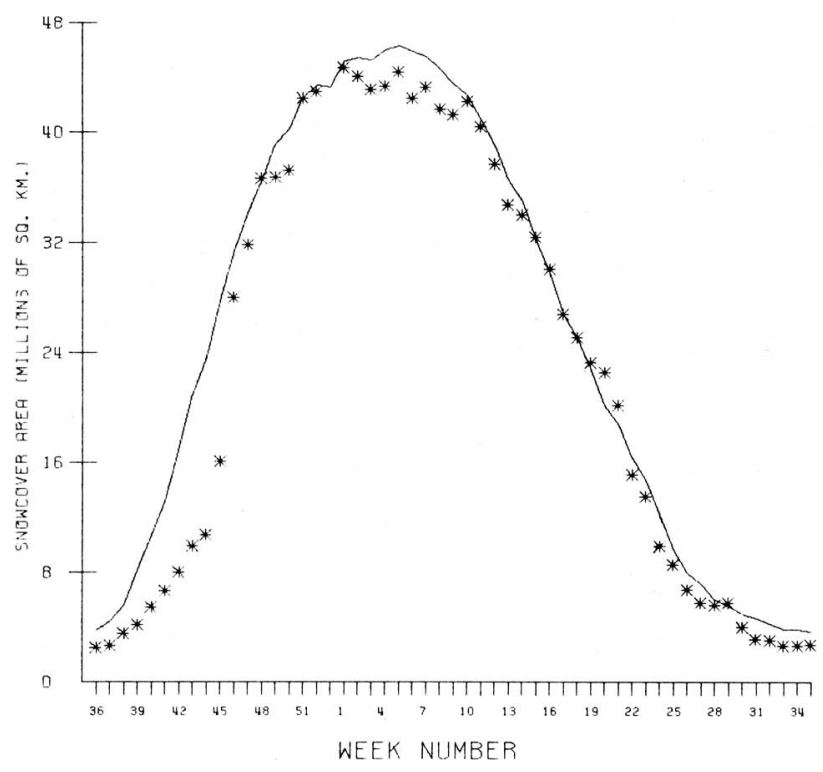

FIG. 3. Digitized Northern Hemisphere weekly snow cover areas for the period 1968-69 (*) compared to the 14-year average weekly snow cover areas (line).

fore, the first step was to compute, using the mathematical relationship inherent in this projection, the true geographic area of each grid box. This information was then stored in the data matrix and utilized each time a series of grid boxes was examined for snow cover area.

With the use of the grid box matrix, the snow cover areas were computed for each week of the data period for North America, Eurasia, and the Northern Hemisphere. These weekly snow cover areas were averaged to create a 14-year average weekly snow cover area data set for the three geographic areas. Using these data, (and noting that minimum snow cover occurred, on the average, during the 35 th week), we defined an average "snow cover season" to begin on week

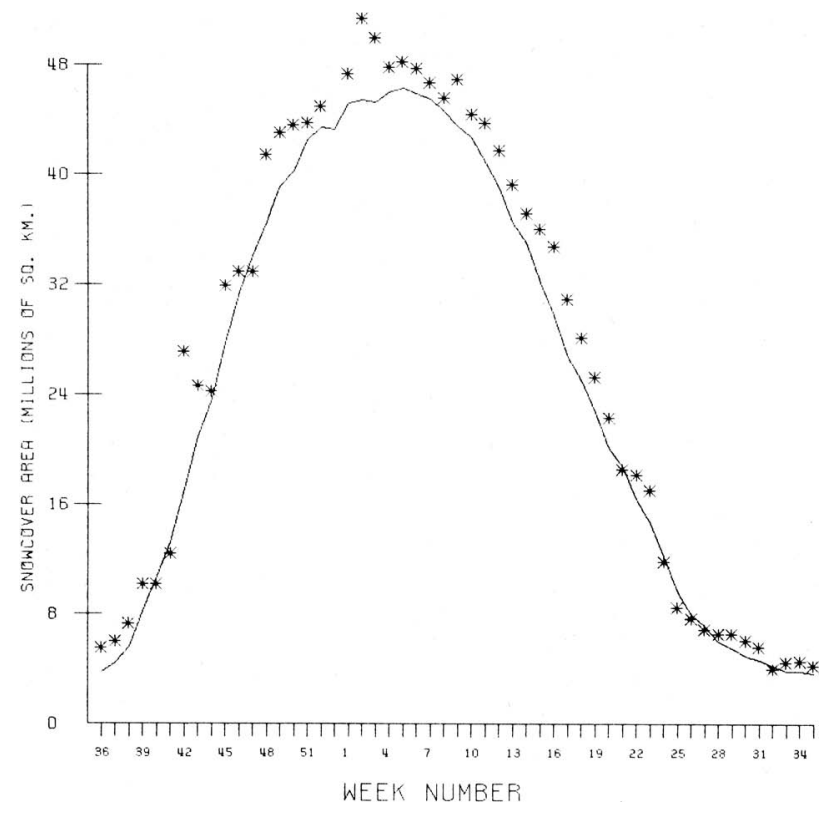

FIG. 4. As in Fig. 3, except for the period 1978-79.

36 and end in week 35 of the following year. The observed weekly snow cover areas for each of the 14 snow cover seasons for the Northern Hemisphere could then be plotted against the average snow cover areas. Figure 3 illustrates the weekly snow cover areas for a snow season with a relatively small snow cover and Fig. 4 illustrates the weekly snow cover areas for a snow season with a relatively large snow cover. An examination of these two snow seasons as well as the other 12 seasons reveals that, generally, there has been an increase in the maximum winter snow cover area for the Northern Hemisphere. Earlier and more extensive snow cover in the fall and slower ablation in the spring have predominated during the latter half of the study period. The recent heavy snow cover

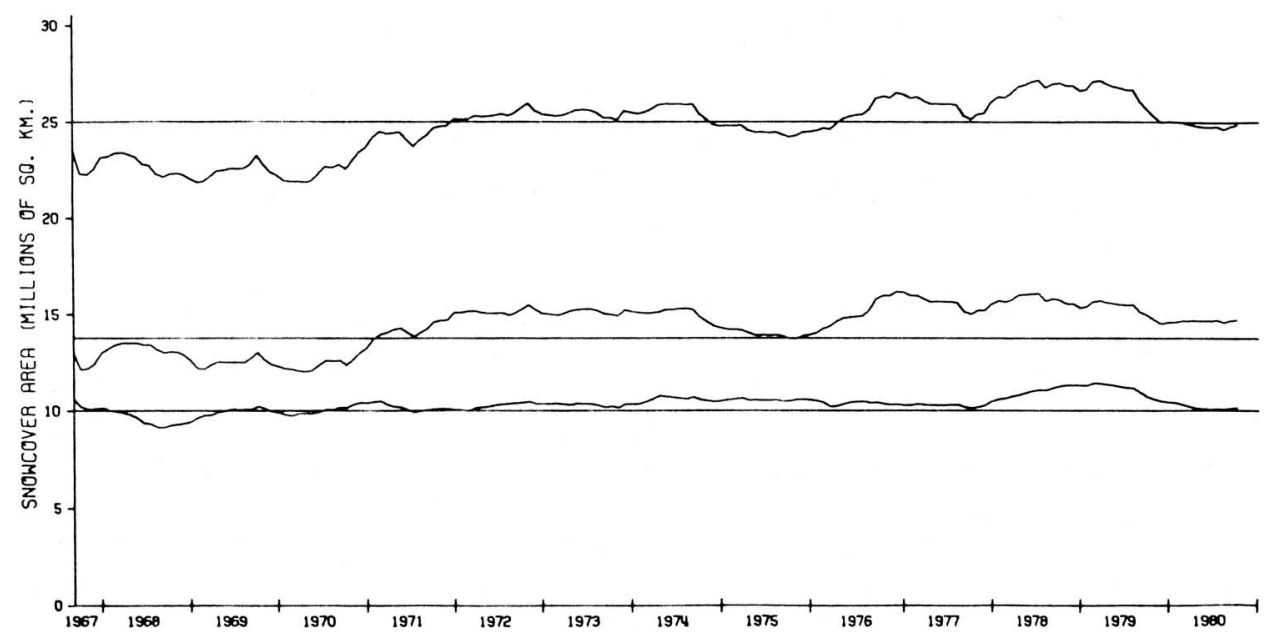

FIG. 5. Running means of snow cover areas for North America (lower curve), Eurasia (middle curve), and the Northern Hemisphere (upper curve), computed from the digitized weekly snow and ice cover charts. 


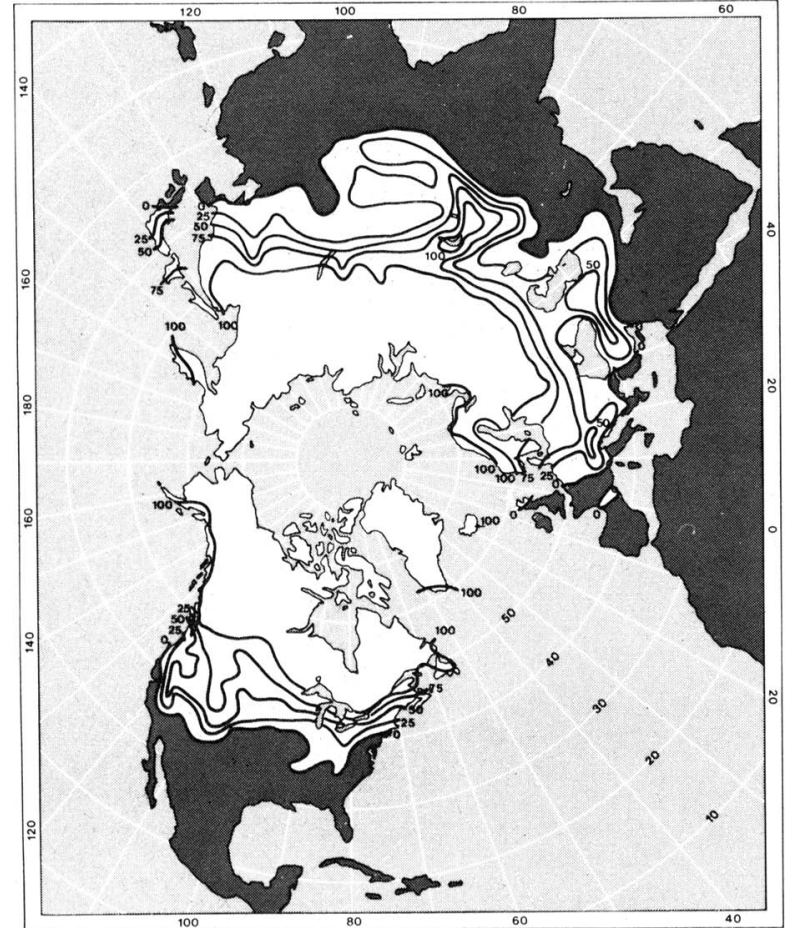

FIG. 6. Average snow cover frequency, calendar week number 10, for the Northern Hemisphere. The $50 \%$ isoline, for example, indicates that there was a snow cover during $50 \%$ of the study period for the specific week.

seasons of 1977-78 and 1978-79 are excellent examples of this variation.

Three 52-week running means were generated for the entire set of weekly snow cover area data and are presented in Fig. 5. This procedure is similar to that used by Kukla and Kukla (1974), Lamb and Morth (1978), and Matson and Wiesnet (1981) to remove the annual cycle and emphasize the interannual variations. Figure 5 indicates that there has been an overall increase in snow cover area from 1966 through 1980 in Eurasia and North America, as well as in the Northern Hemisphere. This figure agrees reasonably well with those published by Kukla and Kukla (1974), Lamb and Morth (1978), and Matson and Wiesnet (1981). It is also clear from this figure that the Northern Hemisphere curve is dominated by variations in the Eurasian snow cover. Major fluctuations have occurred in the Northern Hemisphere snow cover during the study period. The light snow cover at the beginning of the data record was followed by an abrupt increase during 1971-72, which also was noted by Kula and Kukla (1974). This increase may be partially related to the improved mapping of the summer snow cover in the Himalayas. It was followed by a two-year period of less extensive snow cover during 1974-75 and 1975-76. Prolonged and extensive snow cover recurred during the $1976-77$ to $1978-79$ period. Just when it was anticipated that there might be a trend toward greater hemispheric snow cover, the winters of 1979-80 and 1980-81 occurred with their mild temperatures and less extensive snow cover. However, the latest snow cover season (1981-82, not illustrated in Fig. 5) has seen several weekly snow cover values during January and early February that approach the maximum observed during the study period.

The heavy snow cover seasons of 1977-78 and 1978-79 represent the largest snow cover areas plotted in Fig. 5 for both the Northern Hemisphere and North America. The unprecedented cold winters in the contiguous United States during 1977-78 and 1978-79 were documented by Diaz and Quayle (1980) and the extensive and record-breaking snow covers of these two seasons were documented by Wiesnet and Matson (1979) and Matson et al. (1979). It would seem a good assumption that snow cover and temperature anomalies are interrelated (Dewey, 1977; Namias, 1964, 1978a; Wagner, 1973). However, the difficulty arises in determining to what extent the record-breaking cold caused the recordbreaking snow cover or to what extent the snow cover caused the temperature anomaly. Further research is necessary to prove or refute this assumption.

\section{b. Northern Hemisphere snow over frequencies}

Average weekly snow cover frequency maps were computed by determining the frequency of snow cover for each week averaged over the study period. Figure 6 (week No. 10) is an example of the weekly "climatology" of snow cover. An examination of the $100 \%$ boundary on each map illustrates on a weekly basis where there was always a snow cover. The variation in the location of the $50 \%$ boundary from map to map can be used to describe the average location of the snow cover boundary on a weekly basis, and the $0 \%$ boundary is useful in expressing the maximum extent of snow cover that could be expected for any given week. Until the creation of this digital snow cover archive, the climatology of snow cover consisted of point measurements of snowfall and/or snow on the ground, and maps indicating average snow on the ground as of the end of a month. There now exists a climatology of Northern Hemisphere snow cover with weekly temporal resolution and, it is hoped, much greater spatial resolution, which can be of assistance to those planning (well in advance) outdoor activities of any nature (construction, military, recreational, etc.).

Yearly (i.e., week 36 of each year through week 35 of the next year) snow cover frequency maps for the Northern Hemisphere were computed from the weekly data. These frequency maps were prepared by computing, for each grid box, the fractional percentage of the time that it was snow covered during each snow cover season. The usefulness of this product can be demonstrated by comparing two contrasting snow cover seasons. Figure 7 illustrates snow cover frequency during a light snow cover season (1968-69) and Fig. 8 during a heavy snow cover season (1978-79). A comparison of these two figures reveals not only that snow cover extended farther south in Eurasia and North America in 1978-79, but that in many locations the frequency was approximately $10 \%$ higher. The yearly snow cover frequency maps for each snow cover season are, therefore, useful for showing the predominant spatial patterns of Northern Hemisphere snow cover as well as the year-to-year variations in these patterns. Snow cover extent and duration reflect the upper-level circulation; therefore, interannual changes in the predominant circulation patterns can be inferred from these maps. 


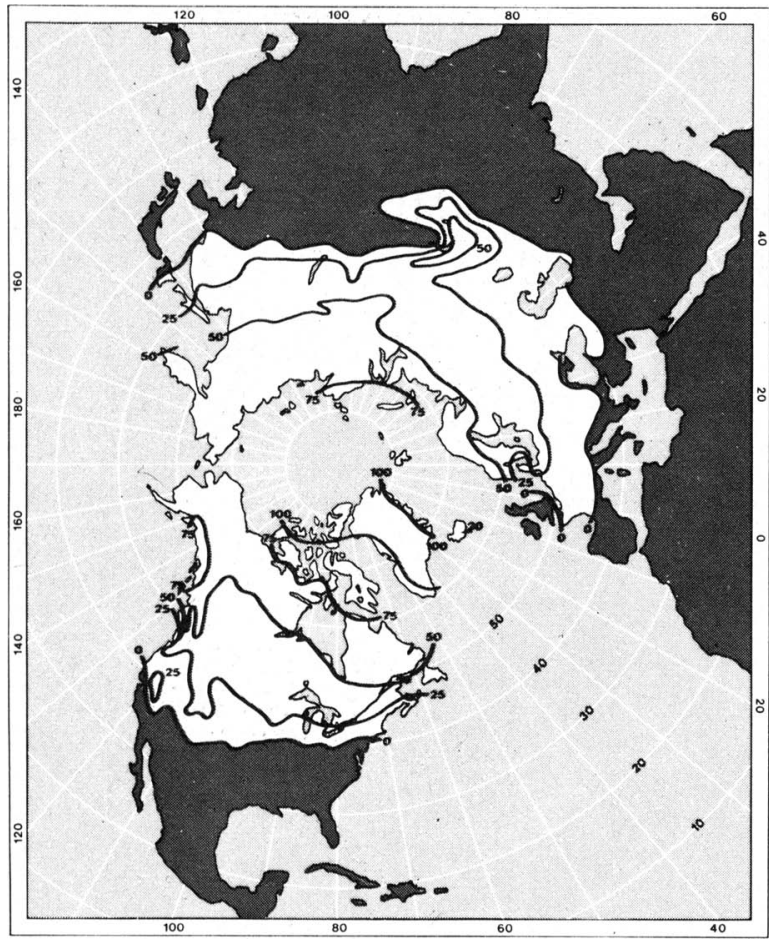

FIG. 7. Snow cover frequency for the Northern Hemisphere from week 36 of 1968 to week 35 of 1969 . The $50 \%$ isoline, for example, indicates that there was a snow cover $50 \%$ of the time during this specific snow cover season.

The comparison of the observed frequency of snow cover during each snow cover season with the average snow cover frequency should be useful for showing snow cover frequency spatial variations or anomalies. A series of frequency anomaly maps were created by comparing the overall average frequency values with each snow cover season's values. The snow cover frequencies stored in digital form and illustrated in Figs. 7 and 8 using isolines could now be expressed in the form of frequency anomalies. Figures 9 and 10 illustrate (using light gray for $5 \%$ or more below average and dark gray for $5 \%$ or more above average) the snow cover frequency anomalies for the 1968-69 and 1978-79 snow cover seasons, respectively. The light snow cover of 1968-69 is illustrated dramatically in both Eurasia and North America, with large areas shown as having below-average snow cover frequency. In fact, the digitized output indicated negative (below average) values as large as $25 \%$ for portions of Eurasia. A comparison of Figs. 9 and 10 confirms what might be expected; that is, even with an extensive hemisphere departure from the average snow cover, there are still regions experiencing concurrent opposite snow cover anomalies. For example, in 1968-69, while much of the Northern Hemisphere was below average, the Pacific Northwest, the Central Plains of the United States, and portions of Central Europe were $5-15 \%$ above average in snow cover frequency. The record-breaking snow cover of 1978-79 (Wiesnet and Matson, 1979 ) is portrayed quite clearly in Fig. 10, where only $3 \%$ of the grid boxes indicated below-average snow cover in North America.

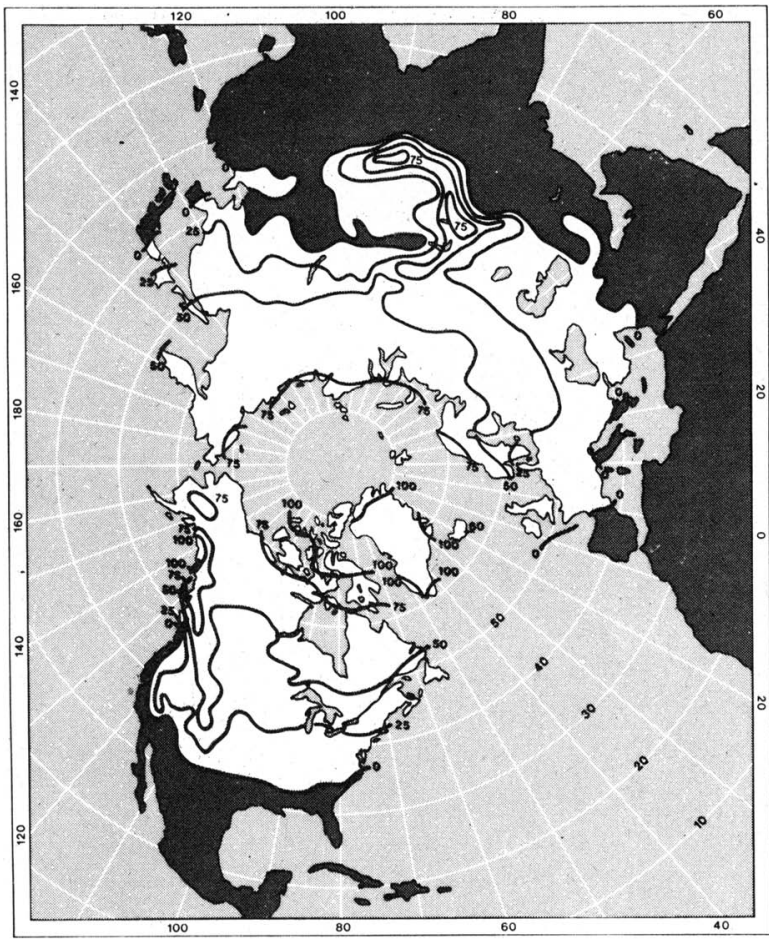

FIG. 8. As in Fig. 7, except for week 36 of 1978 to week 35 of 1979.

\section{A comparison of the digitized mean annual snow cover climatology with previously published climatologies}

The digitized data created in this study were averaged over the entire study period to create an annual snow cover climatology. Figures $11 \mathrm{a}-\mathrm{c}$ illustrate this climatology in comparison with climatologies of snow cover published by Lamb (1972) and by WMO (1975). It is significant to note that the data used to prepare their climatologies were derived from surface observations of snow on the ground. The time periods utilized to create the climatologies vary among the three maps, with Lamb (1972) using the period (1900-50 and WMO using "records of several decades" (WMO, 1975, p. 208). Any isoline could have been chosen for the digitized map, but the isolines chosen for Figs. 11a-c were the only ones compatible for all three climatologies.

The greatest degree of similarity among Figs. $11 \mathrm{a}-\mathrm{c}$ is evident when examining the limit of observed snow cover that is illustrated by the $0 \%$ boundary. Only minor differences occur for this boundary. For example, the WMO (Fig. 11c) boundary in the Middle East is $3^{\circ}$ latitude farther north than the boundaries are in Figs. $11 \mathrm{a}$ and $11 \mathrm{~b}$. There are also minor differences among the three maps in the interpretation of snow cover in England and Spain. The Arctic snow cover climatologies are also similar, as illustrated by the location and pattern of the $70 \%$ and $100 \%$ boundaries.

Significant differences are evident, however, when examining the snow cover climatologies of the middle latitudes $\left(30^{\circ}-60^{\circ} \mathrm{N}\right)$. It is difficult to directly compare the frequencies indicated on the three maps, due to the variation in data 


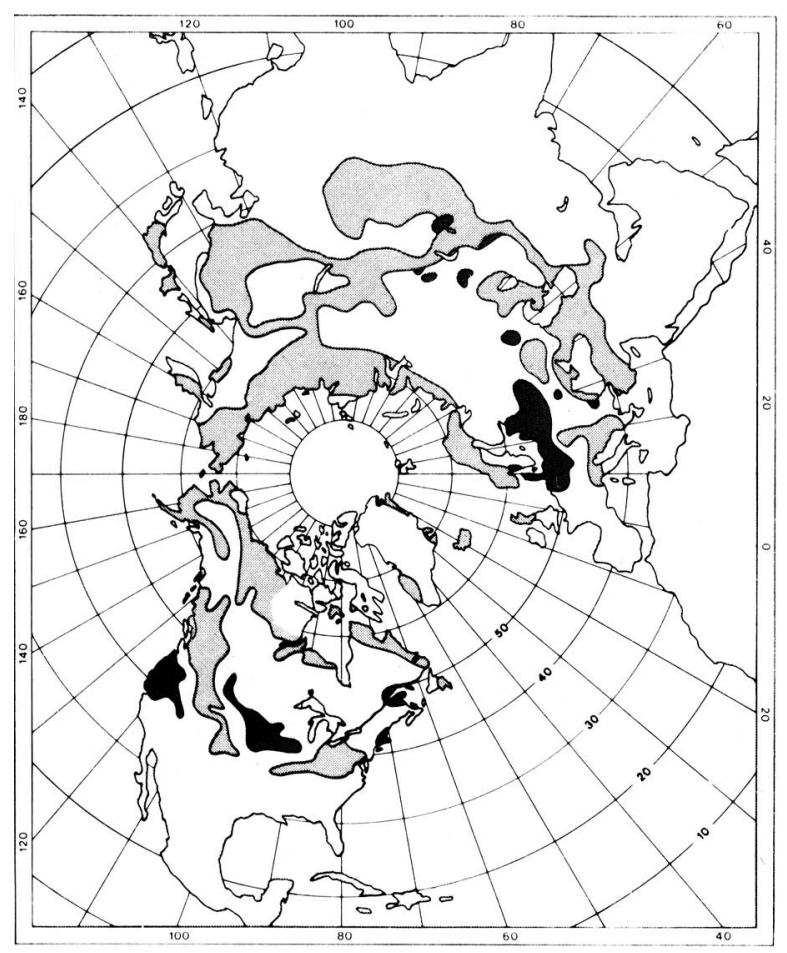

FIG. 9. Snow cover frequency anomalies in the Northern Hemisphere for the 1968-69 snow cover season (week number 36 in 1968 through week number 35 in 1969). Light gray shading indicates frequencies $5 \%$ or more below the 14-year average and dark gray shading indicates frequencies $5 \%$ or more above the 14-year average.

periods; however, it is obvious that the digitized map prepared in this study provides significantly more information on the snow cover climatology of the western North American mountainous region, as well as the Hindu Kush, Pamirs, and the Tibetan Plateau region of Asia, than do the other two maps. Both Figs. $11 \mathrm{~b}$ and $11 \mathrm{c}$ have very generalized analyses of snow cover frequencies in these areas. Not only is there greater detail in the snow cover climatology that used the satellite-derived data, but there also is evidence that these previously existing climatologies greatly underestimated the frequency of snow cover in these two regions. For example, the digitized frequencies of snow cover in the western North American region exceeded $70 \%$, yet the frequencies observed for the same area in Figs. $11 \mathrm{~b}$ and $\mathrm{c}$ were, respectively, 0-30\% and $0-50 \%$. In the Asian mountainous region, the digitized frequencies also exceeded $70 \%$; the previously published climatologies illustrated only a $0-30 \%$ range.

\section{Potential uses for a digital archive of snow cover}

An analysis of the hemispheric snow cover over a period of years can be used as an indicator of short-term climatic variation. However, the greatest potential use for this data base is in the area of short- and long-range atmospheric forecasting. Through the use of contingency analysis, it might be possible

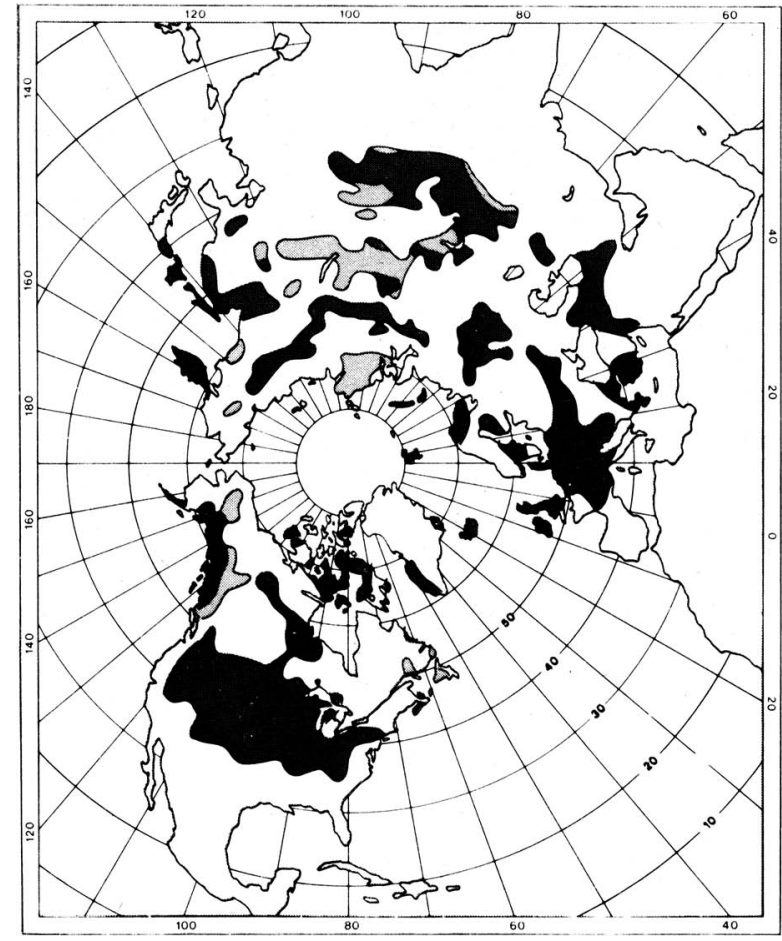

Fig. 10. As in Fig. 9, except for the 1978-79 snow cover season.

to determine whether the snow cover of a given season can be related to the expected snow cover and atmospheric patterns during the next season. Kukla and Kukla (1974), for example, suggested that the anomalous weather patterns of 1972 and 1973 could have been connected with the deficit in surface heat exchange that resulted from an increase in the mean annual snow cover in the Northern Hemisphere the previous year. Namias $(1964,1978 a)$ has related the persistence of abnormally cold (or warm) seasonal temperatures in the western United States to excess (or deficient) snow cover in the region. He $(1962,1963 \mathrm{a})$ also presented evidence that variations, both spatial and temporal, in the location of the seasonal snow cover are related closely to the circulation of the upper atmosphere. Lamb (1972), in summarizing these effects, has noted that, because of the radiative properties of snow, an extensive snow cover on land produces a strong horizontal thermal contrast along the boundary between the cold snow-covered surface and the warmer bare ground. This ultimately results in a differential heating of the overlying atmosphere. A snow or ice surface of sufficient longitudinal extent introduces a stabilizing factor in winter that apparently guarantees the existence of a more or less fixed cold trough in the higher latitudes. During the early development and testing of a forecast model for maximum/minimum temperatures (Klein and Lewis, 1970; Klein et al., 1971), snow cover was considered as a possible predictor. Intuitively, it was assumed that snow cover should have a significant influence on observed temperatures, resulting in lower temperatures than would have occurred over bare ground. Dewey (1977) also demonstrated the potential usefulness of snow cover data in the forecasting of daily temperatures. 


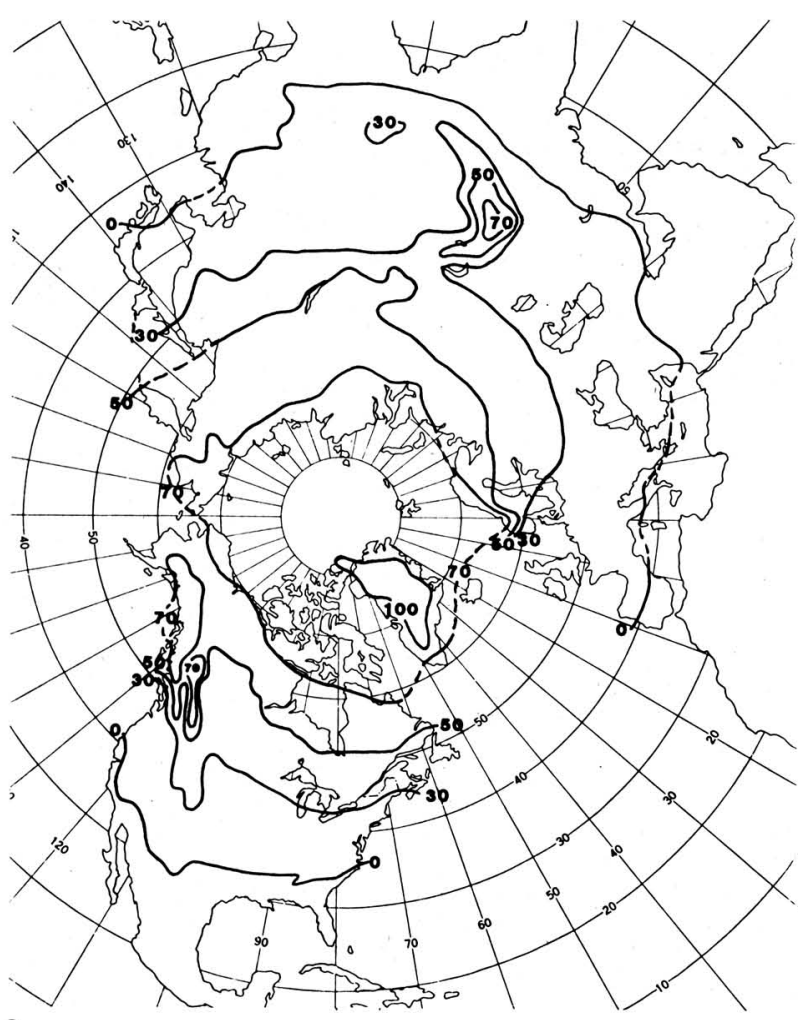

a

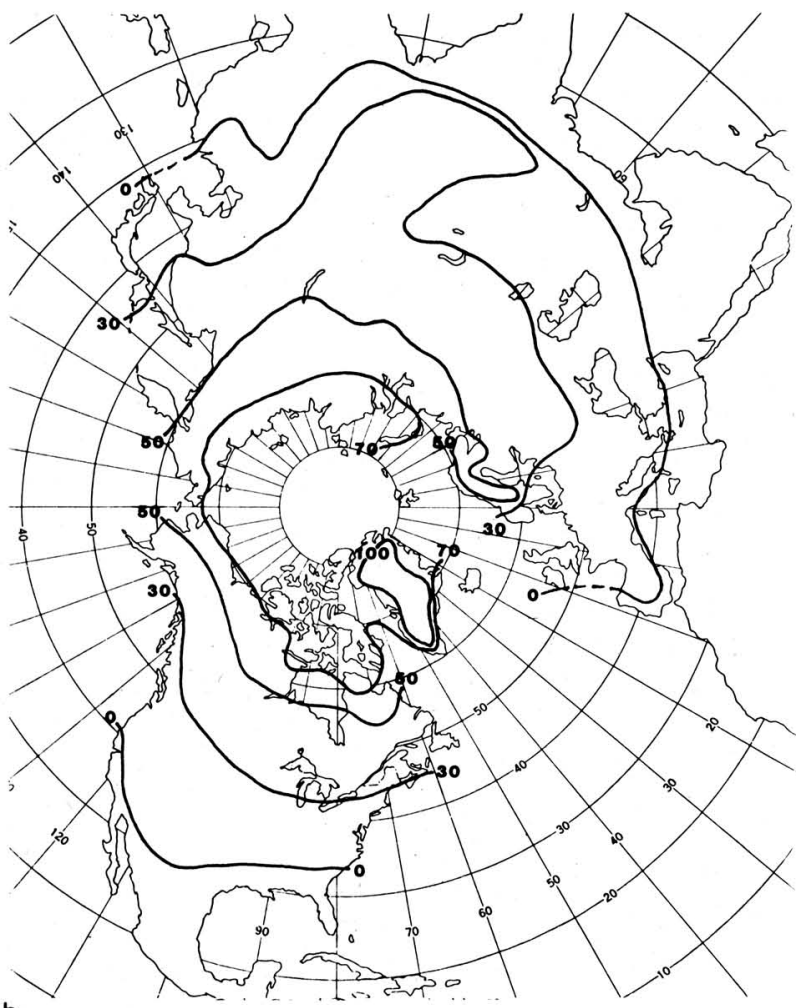

b

Lamb (1972) and Namias (1963b, 1966, 1978b) have described how a snow cover can have a positive feedback as it interacts with the upper winds. The feedback exists when the surface depressions are steered around the southern limit of

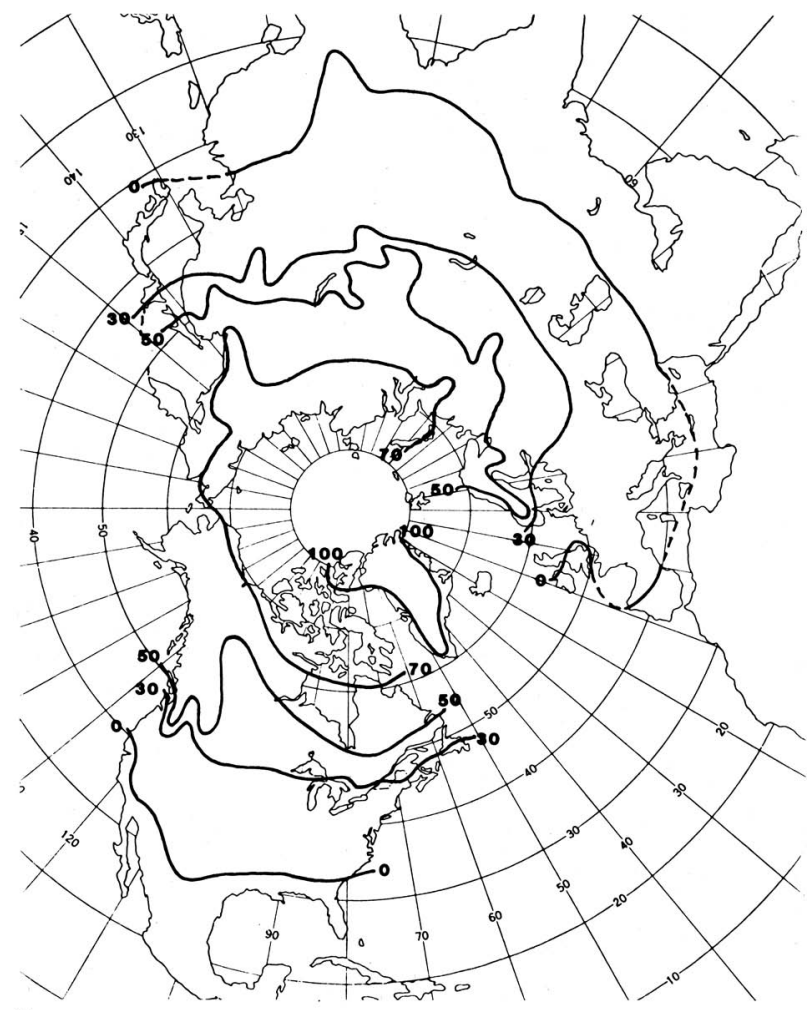

C

FIG. 11. a) Average annual frequency of Northern Hemisphere snow cover derived from the satellite-based digital archive created in this study. The $30 \%$ isoline, for example, indicates that there was a snow cover, on the average, during $30 \%$ of each year in the 1966-80 study period. b) Average percentage of the time during the year that low ground was more than half covered with snow at the morning observation. (From Lamb; 1972.) c) Average duration of snow cover (in percentage of year) on land. (From WMO, 1975.)

the cold snow-covered region by the upper winds. This helps to maintain the snow cover by adding to its depth and horizontal extent near its western, southern, and eastern limits (in the Northern Hemisphere). This feedback would tend to expand the areal extent of the snow cover and lead to its persistence later into the thawing season, as well as further entrenching the upper-level cold trough. Lamb (1972) used the summer of 1968 in northwest Siberia as an example of this. It was exceptionally cold in this region, and the previous winter's snow lingered on the low ground into the summer. This snow and the resulting cold and sodden ground, in addition to the thick and extensive sea ice to the north, kept the season's solar radiation from ameliorating the cold anomaly. A sharp upper-level cold trough was maintained over the region and was related to an early autumn. Renewed snowfall occurred in late July and early August, with a new snow cover established by mid-September.

Because the onset of the summer monsoon in India is related to the northward jump of the polar jet in Asia, variations in winter snow cover have further implications. Hahn and Shukla (1976) noted an inverse relationship between winter snow cover over Eurasia and summer monsoon rainfall over India. Graphs of year-to-year variations of these quantities for the period 1967-75 indicate that winters with 
extensive (or little) snow cover over Eurasia tended to be followed by summers with less (or more) rainfall over India. The northward jump of the jet axis across the Tibetan Highlands apparently is delayed in individual years by a lingering snow cover over the extensive middle Asian Highlands.

\section{Summary and conclusions}

It has been suggested by numerous researchers that there is a need for continued studies of the interactions between snow cover and the circulation of the atmosphere. It also has been suggested that snow cover data would be useful in studies of short-term climatic variability. Several researchers have proposed that, due to a series of feedback mechanisms, the snow cover of a given season could be related to the expected snow cover and atmospheric patterns of the next season.

The primary limiting factor in a quantitative study of any of these interactions has been the lack of digitized snow data. Snow cover data have existed since the late 1960s in the form of the NESS-produced Northern Hemisphere Weekly Snow and Ice-Cover Charts. Therefore, the decision was made to create a digital archive of these maps. Having accomplished this task, it was the purpose of this project to create a series of climatological products from this data base. The use of satellite-derived snow cover charts has increased both the spatial and temporal resolution of the various snow cover climatologies. Historically (before the use of satellite imagery), snow cover data were based on point observations, with large areas unrepresented, resulting in only estimates of snow cover extent. Most snow cover climatologies were monthly and/or annual snow cover maps, and many were created subjectively. Using the digitized weekly data that were produced in this study, it was possible to create maps of snow cover extent (area) and frequency for the entire Northern Hemisphere on a time scale ranging from weekly to annual averages.

Average weekly Northern Hemisphere snow cover areas were calculated from the data archive. A series of charts was created, displaying the weekly observed snow cover areas for each snow cover season in conjunction with the average snow cover areas. These charts indicate that there has been a trend toward earlier accumulation, increased maximum extent, and later ablation. A time series plot was created for Eurasia and North America, as well as the Northern Hemisphere snow cover area data. From this plot, it became apparent that there has been an increasing trend in snow cover area over the 14-year time period. Weekly and annual snow cover frequency maps were derived quantitatively and several examples were displayed in this report. Knowledge of the expected frequency of snow cover in a given region would appear to be useful for planning purposes. Snow cover frequency anomaly maps were created to illustrate the spatial and quantitative variations in snow cover frequency from snow season to snow season. These anomaly maps were useful in demonstrating the recent trend toward more extensive snow cover. It was also noted that there is an apparent relationship between snow cover and atmospheric circulation, in that the anomalous snow cover of 1977-78 and 1978-79 accompanied two anomalously cold winters in North America.
The average annual frequency of snow cover for the Northern Hemisphere was created from the weekly digitized charts. This snow cover climatology was compared to the climatologies developed by Lamb (1972) and WMO (1975). The digitized snow cover climatology compared quite favorably to the other climatologies, and the advantage of using satellite-derived data was made obvious through increased snow cover detail in western North America and Asia.

Numerous potential uses exist for this archive of weekly snow cover data. For example, correlation analyses could be performed to statistically relate the snow cover data to various atmospheric circulation parameters. Using hindcasting techniques, both short range and long range (monthly to seasonal) forecasters can test to see if inclusion of snow cover data increases the accuracy of their forecast equations. Radiation budget studies on a hemispheric scale will also be able to utilize these data. It is anticipated that numerical modelers will be able to use these snow cover data as input parameters to their hemispheric circulation models. Hydrological forecasting studies might also benefit from access to this data base. As the digital archive grows (NESS took over the digitizing of the weekly charts starting with the first week in December 1980), it should increase in importance as a source of data for those interested in short-term climatic variability. The digital archive has been presented to NESS and is accessible (complete with documentation) in the form of magnetic tape and microfilm from NOAA/EDIS, Room 100, World Weather Building, Washington, D.C. 20233.

Acknowledgments. This research project was conducted for the National Earth Satellite Service, Earth Sciences Laboratory, under NOAA grant No. NA80AAA02240. Appreciation is extended to the two technical advisors, Michael Matson and Donald Wiesnet, as well as to their staff, for their collective advice and assistance.

\section{References}

Dewey, K. F., 1977: Daily maximum and minimum temperature forecasts and the influence of snow cover. Mon. Wea. Rev., 105, 1594-1597.

Diaz, H. F., and R. G. Quayle, 1980: An analysis of the recent extreme winters in the contiguous United States. Mon. Wea. Rev., 108, 687-699.

Dickson, R. R., and J. Namias, 1976: North American influences on the circulation and climate of the North Atlantic sector. Mon. Wea. Rev., 104, 1255-1265.

Hahn, D. G., and J. Shukla, 1976: An apparent relationship between snow cover and Indian monsoon rainfall. J. Atmos. Sci., 33, 2461-2462.

Klein, H. W., and F. Lewis, 1970: Computer forecasts of maximum and minimum temperatures. J. Appl. Meteorol., 9, 350-359.

,-- , and G. A. Hammons, 1971: Recent developments in automated $\mathrm{max} / \mathrm{min}$ temperature forecasting. J. Appl. Meteorol., 10, 916-920.

Kukla, G. J., and H. J. Kukla, 1974: Increased surface albedo in the Northern Hemisphere. Science, 183, 709-714.

Lamb, H. H., 1955: Two-way relationship between the snow or ice 
limit and $1,000-500 \mathrm{mb}$ thickness in the overlying atmosphere. Quart. J. Roy. Meteorol. Soc., 81, 172-189.

-1972: Climate: Present, Past and Future, Volume 1. Methuen and Company, Ltd., London, 613 pp.

- and H. T. Morth, 1978: Arctic ice, atmospheric circulation and world climate. Geograph. J., 144, 1-22.

Matson, M., 1977: Winter snow-cover maps of North American and Eurasia from satellite records, 1966-1976. NOAA Tech. Memo. NESS 84, Washington, D.C., 28 pp.

- and D. R. Wiesnet, 1981: New data base for climate studies. Nature, 289, 451-456.

,-- , C. P. Berg, and E. P. McClain, 1979: New data and new products: The NOAA/NESS continental snow cover data base. Proceedings, Fourth Annual Climate Diagnostics Workshop, 16-18 October 1979, Madison, Wis., NOAA, Washington, D.C., pp. 351-364.

Namias, J., 1960: Snowfall over eastern United States: Factors leading to its monthly and seasonal variations. Weatherwise, 13, 238-247.

- 1962: Influence of abnormal surface heat sources and sinks on atmospheric behavior. Proceedings, Symposium on Numerical Weather Prediction, 7-13 November 1960, Tokyo, Meteorological Society of Japan, Tokyo, pp. 615-627.

- 1963a: Surface-atmospheric interactions as fundamental causes of drought and other climatic fluctuations. In Short Period Climatic Variations: Collected Works of J. Namais, 1934 through 1974. University of California Press, San Diego, 905 pp.

- 1963b: Large-scale air-sea interactions over the North Pacific from summer 1962 through the subsequent winter. J. Geophys. Res., 68, 6171-6186.

- 1964: A 5-year experiment in the preparation of seasonal outlooks. Mon. Wea. Rev., 92, 449-464.

_ 1966 : Large-scale air-sea interactions as primary causes of fluctuations in the prevailing weather. Trans. New York Acad. Sci., 29, 183-191.

- 1978a: Persistence of U.S. seasonal temperatures up to one year. Mon. Wea. Rev., 106, 1557-1567:

- , 1978b: Multiple causes of the North American abnormal winter 1976-77. Mon. Wea. Rev., 106, 279-295.

Robock, A., 1980: The seasonal cycle of snow cover, sea ice, and surface albedo. Mon. Wea. Rev., 108, 267-285.

Wagner, A. J., 1973: The influence of average snow depth on monthly mean temperature anomaly. Mon. Wea. Rev., 101, 624-626.

Wiesnet, D. R., and M. Matson, 1979: The satellite-derived Northern Hemisphere snowcover record for the winter of 1977-78. Mon. Wea. Rev., 107, 928-933.

Winston, J. S., A. Gruber, T. I. Gray, M. S. Varnadore, C. L. Earnest, and L. P. Mannello, 1979: Earth-Atmosphere Radiation Budget Analyses Derived from NOAA Satellite Data, June 1974-February 1978, vols. 1 and 2. Climate Analysis Center, NOAA, Washington, D.C.

World Meteorological Organization, 1975: The physical basis of climate and climate modelling. Report of the International Study Conference in Stockholm, 29 July-10 August 1974. GARP Publ. Ser. 16. (Available through UNIPUB, 345 Park Ave. South, New York, N.Y. 10010.)

announcements (continued from page 1131)

\section{Change in NWS college graduate meteorologist recruiting}

To improve its short-term, small-scale forecast capabilities, the National Weather Service (NWS) requires the services of more meteorologists at its local service offices. These offices have been staffed historically by paraprofessionals. As vacancies occur, however, NWS intends to fill a substantial number of positions with college graduates. Staffing these local offices with undergraduate meteorologists directly from colleges and universities will be NWS's major vehicle of recruiting meteorologists in the future.

Several opportunities for career advancement to professional positions have been established for those interested in filling these local service office positions. Individuals hired under this new policy can expect a competitive starting salary progressing to a salary of about $\$ 28000$ per year in about five years, in addition to the full benefits package afforded career federal employees.

In the past, any college graduates interested in meteorological careers in the NWS applied to and were referred to NWS by the U.S. Office of Personnel Management (OPM) Meteorologist registers. In order to meet the objectives of NWS's new hiring emphasis, it will be necessary for those individuals to apply to OPM Meteorological Technician registers, which will be used more actively by the NWS and will be established for a far greater number of locations throughout the country. Successful candidates will serve an "intership" in a technician position at a local service office and later may convert to a full professional meteorological position. Some degree of mobility may be required. For further information, contact the following offices:

In Maine, New Hampshire, Vermont, New York, Massachusetts, Connecticut, Rhode Island, New Jersey, Pennsylvania, Ohio, West
Virginia, Maryland, Virginia, North Carolina, South Carolina, and the District of Columbia: National Weather Service, Eastern Region Personnel Office, 585 Stewart Ave., Garden City, N.Y. 11530 Attn: Steve Brienza, OA/WFE6x3 tel: (516) 228-5467;

In New Mexico, Texas, Oklahoma, Arkansas, Louisiana, Mississippi, Tennessee, Alabama, Georgia, and Florida: National Weather Service, Southern Region Personnel Office, 819 Taylor St., Rm. 10E09, Ft. Worth, Tex. 76102 Attn: Rosalie Haresnape, OA/WFS6 tel: (817) 334-2663;

In North Dakota, South Dakota, Nebraska, Kansas, Wyoming, Colorado, Minnesota, Iowa, Missouri, Wisconsin, Illinois, Michigan, Indiana, and Kentucky: National Weather Service, Central Region Personnel Office, 601 E. 12th St., Rm. 1835, Kansas City, Mo. 64106 Attn: Gloria Lynam, OA/WFC6 tel: (816) 758-3196;

In Washington, Oregon, California, Nevada, Idaho, Montana, Utah, and Arizona: National Weather Service, Western Region Personnel Office, Federal Bldg., 125 South State St., Salt Lake City, Utah 84147 Attn: Annette Sund, OA/WFW6x 1 tel: (801) 588-5128;

In Alaska: National Weather Service, Alaska Region Personnel Office, 701 C St., Anchorage, Alaska 99513 Attn: Jane Baldwin, OA/WFA6 tel: (907) 271-5086; and

In Hawaii: National Weather Service Office, Prince Kuhio Federal Bldg., 300 Ala Moana Blvd., P.O. Box 50027, Honolulu, Hawaii 96850 tel: (808) 546-5678. 